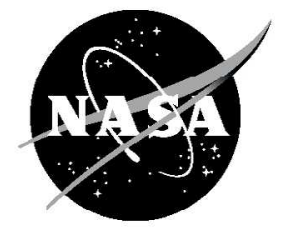

\title{
An Excess Broadband Noise Observed With Overexpanded Jets
}

\author{
K.B.M.Q. Zaman, James E. Bridges, and C.A. Brown
} Glenn Research Center, Cleveland, Ohio 


\section{NASA STI Program . . . in Profile}

Since its founding, NASA has been dedicated to the advancement of aeronautics and space science. The NASA Scientific and Technical Information (STI) program plays a key part in helping NASA maintain this important role.

The NASA STI Program operates under the auspices of the Agency Chief Information Officer. It collects, organizes, provides for archiving, and disseminates NASA's STI. The NASA STI program provides access to the NASA Aeronautics and Space Database and its public interface, the NASA Technical Reports Server, thus providing one of the largest collections of aeronautical and space science STI in the world. Results are published in both non-NASA channels and by NASA in the NASA STI Report Series, which includes the following report types:

- TECHNICAL PUBLICATION. Reports of completed research or a major significant phase of research that present the results of NASA programs and include extensive data or theoretical analysis. Includes compilations of significant scientific and technical data and information deemed to be of continuing reference value. NASA counterpart of peer-reviewed formal professional papers but has less stringent limitations on manuscript length and extent of graphic presentations.

- TECHNICAL MEMORANDUM. Scientific and technical findings that are preliminary or of specialized interest, e.g., quick release reports, working papers, and bibliographies that contain minimal annotation. Does not contain extensive analysis.

- CONTRACTOR REPORT. Scientific and technical findings by NASA-sponsored contractors and grantees.
- CONFERENCE PUBLICATION. Collected papers from scientific and technical conferences, symposia, seminars, or other meetings sponsored or cosponsored by NASA.

- SPECIAL PUBLICATION. Scientific, technical, or historical information from NASA programs, projects, and missions, often concerned with subjects having substantial public interest.

- TECHNICAL TRANSLATION. Englishlanguage translations of foreign scientific and technical material pertinent to NASA's mission.

Specialized services also include creating custom thesauri, building customized databases, organizing and publishing research results.

For more information about the NASA STI program, see the following:

- Access the NASA STI program home page at http://www.sti.nasa.gov

- E-mail your question via the Internet to help@ sti.nasa.gov

- Fax your question to the NASA STI Help Desk at 301-621-0134

- Telephone the NASA STI Help Desk at $301-621-0390$

- Write to: NASA Center for AeroSpace Information (CASI) 7115 Standard Drive Hanover, MD 21076-1320 
NASA/TM-2009-215603

AIAA-2009-0289

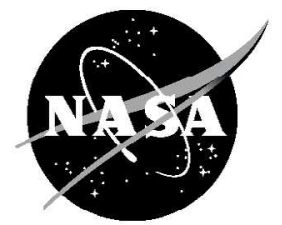

\section{An Excess Broadband Noise Observed With Overexpanded Jets}

K.B.M.Q. Zaman, James E. Bridges, and C.A. Brown Glenn Research Center, Cleveland, Ohio

Prepared for the

47th Aerospace Sciences Meeting and Exhibit

sponsored by the American Institute of Aeronautics and Astronautics

Orlando, Florida, January 5-8, 2009

National Aeronautics and

Space Administration

Glenn Research Center Cleveland, Ohio 44135 


\section{Acknowledgments}

Support from the Supersonic Project under the Fundamental Aeronautics Program is gratefully acknowledged.

Trade names and trademarks are used in this report for identification only. Their usage does not constitute an official endorsement, either expressed or implied, by the National Aeronautics and Space Administration.

This work was sponsored by the Fundamental Aeronautics Program at the NASA Glenn Research Center.

Level of Review: This material has been technically reviewed by technical management.

Available from

NASA Center for Aerospace Information 7115 Standard Drive

Hanover, MD 21076-1320
National Technical Information Service 5285 Port Royal Road Springfield, VA 22161

Available electronically at http://gltrs.grc.nasa.gov 


\title{
An Excess Broadband Noise Observed With Overexpanded Jets
}

\author{
K.B.M.Q. Zaman, James E. Bridges, and C.A. Brown \\ National Aeronautics and Space Administration \\ Glenn Research Center \\ Cleveland, Ohio 44135
}

\begin{abstract}
Results of an experiment on the characteristics of an excess noise occurring with convergentdivergent (C-D) nozzles in the overexpanded regime are presented in this paper. Data are obtained with five C-D nozzles and a convergent nozzle, all having the same exit diameter. The results clearly establish that the C-D nozzles are noisier in the low Mach number range of the overexpanded regime. This is evidenced from the directivity patterns as well as overall radiated sound power calculations. The excess noise is broadband in nature and is found to be more pronounced with nozzles having a larger half-angle of the divergent section. It appears to occur when a shock resides within the divergent section and results from random unsteady motion of the shock.
\end{abstract}

\section{Introduction}

A broadband noise component occurring in the overexpanded flow regime with convergent-divergent nozzles was investigated earlier in (ref. 1). Relative to a convergent nozzle, at same pressure ratios, this 'excess broadband noise' (to be referred to in the following as 'EBBN') can lead to a large increase in the overall sound pressure levels. Several features distinguish it from the more familiar broadband shock associated noise (BBSN). The phenomenon, as understood thus far, is best explained with the help of the schematic in Figure 1. Following (ref. 2), data trends for OASPL are shown as a function of $M_{j}$ for various cases; here $M_{j}$ is the 'fully expanded jet Mach number' defined in the next section. The dotted (purple) line represents turbulent mixing noise. This curve would be obtained if at each $M_{j}$ an appropriate C-D nozzle were used to obtain perfectly expanded flow. Results from a convergent nozzle are represented by the dashed (blue) curve while that from a given C-D nozzle is shown by the solid (green) curve. At the design Mach number (fully expanded condition), the C-D nozzle generates noise due only to turbulent mixing. Relative to this point, on either left (overexpanded condition) or right (underexpanded condition) the C-D nozzle exhibits higher levels due to BBSN. In the schematics used by Tam (refs. 2 and 3 ), the levels for the convergent nozzle were shown to be approximately the same as those for the C-D nozzle on the low end of the $M_{j}$-range. The focus in those earlier studies was on BBSN occurring at higher $M_{j}$ and attention was not paid to the range of $M_{j}$ below about 1.2. It is in this range the intensities are found to be much larger than the convergent case due to EBBN. This is sketched by the solid (red) line.

As identified in (ref. 1), various features of EBBN distinguished it from BBSN. Unlike the latter, it was observed to persist at shallow polar locations. There was no noticeable shift of the spectral content in frequency between a shallow polar location and locations normal to the jet axis. The amplitudes of EBBN were found to be more pronounced with nozzles having a larger half-angle of the divergent section. The source of EBBN appeared to be tied to unsteady shock motion within the divergent section.

Although a lot was learned in (ref. 1), the full characteristics of EBBN remained uncharted and its mechanism not clearly understood. The following aspects of the experiment reported in (ref. 1) left some ambiguities with regards to the results: (1) The study was conducted with tiny nozzles having nominal diameters of 0.3 in. (2) The nozzles had simple conical divergent sections. Therefore, the flow was never perfectly expanded at the 'design' Mach number and the dip in the OASPL curve (Fig. 1) was never observed. It was not clear if EBBN would occur with well-designed C-D nozzles. (3) The exit diameters 
of the C-D nozzles varied and the results were compared with data from a larger convergent nozzle by scaling all data with respect to the throat diameters. It was desirable to compare the intensity levels for nozzles of same size. There also remained some question whether the noise should be scaled with respect to the throat or the exit diameters.

The ambiguities listed above provided the motivation to carry out a further study. A set of larger C-D nozzles (all with exit diameters of $2 \mathrm{in}$.) were fabricated specifically for this purpose. Preliminary acoustic surveys were conducted in a smaller semi-anechoic facility and the extended abstract for this paper was submitted based on those data. Subsequently, detailed data were acquired in a larger, anechoic facility described in the following. The objective of this paper is to document the results from the latter experiment and provide a discussion with primary focus on the EBBN.

\section{Experimental Facility}

The data were acquired in the Small Hot Jet Acoustic Rig (SHJAR), located in the Aeroacoustic Propulsion Laboratory (AAPL) at the NASA Glenn Research Center (Fig. 2). It is a single flow jet rig that uses 150-psi air supplied by several remotely located compressors. The maximum mass flow rate is $6 \mathrm{lbm} / \mathrm{sec}$. The air passes through a baffled muffler and settling chamber before reaching the nozzle. Two valves, a large main valve and a small vernier valve, control the rate of airflow, providing fine control over the entire range of operating conditions. The AAPL, which houses the SHJAR, is a geodesic dome (60-ft radius) lined with sound absorbing wedges which reduce sound reflection at all frequencies above $200 \mathrm{~Hz}$ (ref. 4). The jet exhaust is directed outside through a large door.

Acoustic measurements in the SHJAR are recorded by an array of 24 microphones. Each microphone is $100 \mathrm{in}$. away from the nozzle exit. They are spaced approximately at $5^{\circ}$ interval from $15^{\circ}$ to $130^{\circ}$. The angular location $\theta$ is referenced to the downstream jet axis. To minimize reflection from the microphone stands, six stands, each holding four microphones, are used. Another computer, called ESCORT, records other variables such as rig temperatures, pressures, and mass flow rate as well as ambient temperature, pressure, and humidity. A DataMAX Instrumentation Recorder (RC Electronics), simultaneously records data from all microphones, using a $90 \mathrm{kHz}$ low-pass filter to limit the bandwidth (at $200 \mathrm{kHz}$ sample rate). Bruel \& Kjaer Nexus amplifiers provide the signal conditioning. Eight seconds of data are recorded at each point. Further details of the facility and description of tests validating the data system can be found in (ref. 4).

Six nozzles are used in the experiment all having an exit diameter of $2 \mathrm{in.}$ and a length of $7.5 \mathrm{in}$. The divergent sections are designed following the method of characteristics. The length of the divergent section varies depending on the design Mach number. Thus, the lengths of the convergent section also vary. A 4th order polynomial fit is used to design the convergent section matching the slope of the upstream hardware and bringing the slope to zero at the throat. Important dimensions of the six nozzles are given in Table 1.

TABLE 1.-NOZZLE DIMENSIONS (IN INCHES) AND OTHER CHARACTERISTICS; ALL NOZZLES ARE 7.5 in. LONG AND HAVE EXIT DIAMETER $D_{e}=2$ in. $M_{j}$ - sub AND $M_{j}$-shock ARE VALUES OF $M_{j}$ WHEN THE SHOCK IS AT THE THROAT AND AT THE EXIT PER ONE-DIMENSIONAL ANALYSIS, $M_{D}$ IS THE DESIGN MACH NUMBER. CORRESPONDING NPR VALUES ARE SHOWN IN THE LAST THREE COLUMNS.

\begin{tabular}{|l|c|c|c|c|c|c|c|c|}
\hline Nozzle & $\begin{array}{c}\text { Throat diameter, } \\
D_{t}\end{array}$ & $\begin{array}{c}\text { Divergent } \\
\text { sec. length }\end{array}$ & $M_{D}$ & $M_{j}$-sub & $M_{j}$-shock & $\begin{array}{c}\text { NPR- } \\
\text { design }\end{array}$ & $\begin{array}{c}\text { NPR-sub } \\
\text { NPR- } \\
\text { shock }\end{array}$ \\
\hline M10 & 2 & 0 & 1.0 & ---- & ---- & 1.893 & -1.355 & 1.501 \\
M14 & 1.8952 & 1.832 & 1.4 & 0.674 & 0.784 & 3.182 & 1.355 & 1.231 \\
M16 & 1.7900 & 2.382 & 1.6 & 0.553 & 0.789 & 4.251 & 1.508 \\
M18 & 1.6702 & 2.630 & 1.8 & 0.454 & 0.842 & 5.746 & 1.152 & 1.590 \\
M22 & 1.4148 & 3.351 & 2.2 & 0.305 & 1.026 & 10.692 & 1.067 & 1.952 \\
M28 & 1.0730 & 4.002 & 2.8 & 0.168 & 1.363 & 27.138 & 1.020 & 3.022 \\
\hline
\end{tabular}

"A suffix ' $T$ ' following a nozzle designation represents tripped boundary layer. 
A computer-aided-design (CAD) drawing of one of the nozzles is shown in Figure 3(a). Figure 3(b) shows the internal wall contours for all nozzles. 'Boundary layer trip' is applied in order to suppress transonic tones, discussed further in the following. The trip consists of four strips of aluminum tape. Each is 0.625 in. wide at the base and about $0.75 \mathrm{in}$. long with the upstream end cut into a triangular shape. The tapes are 0.004 in. thick and applied close to but sufficiently upstream of the throat not to affect its diameter. Figure 3(c) shows a view of the M22T nozzle from the upstream end where the trips are visible. In the following, the 'fully expanded jet Mach number', $M_{j}=\left(\left(\left(p_{0} / p_{a}\right)^{(\gamma-1) / \gamma}-1\right) \frac{2}{\gamma-1}\right)^{1 / 2}$, is used as the independent variable. Here, $p_{0}$ and $p_{a}$ are plenum pressure and ambient pressure, respectively. Note that for imperfectly expanded flows $M_{j}$ is a fictitious Mach number. It is simply a function of nozzle pressure ratio and represents the Mach number at the exit of a nozzle had the flow expanded fully. In Table 1 the values of $M_{j}$ for various flow conditions based on one-dimensional analysis are shown. The notations are defined in the caption and corresponding nozzle pressure ratios $\left(N P R=p_{0} / p_{a}\right)$ are also shown in the table.

For all tripped cases, spectra of the 24 microphone signals are recorded for 12 values of $M_{j}$ covering the range $0.3-2.0$. In addition data are also recorded for the (untripped) M18 and M22 cases. The highest $M_{j}(=2)$ could not be covered for the convergent and the M14 nozzles because the required mass flow rate exceeded the supply. All noise data are corrected for atmospheric attenuation and referenced to 1-foot distance from the nozzle. All data pertain to cold flow, i.e., having the total temperature the same everywhere as in the ambient.

\section{Results}

In order to obtain a clear sense of the operating regimes as well as the nature of the transonic tones first let us consider Figure 4, reproduced from (ref. 5). The frequencies of sharp tones, observed with a small C-D nozzle, are plotted while the driving pressure (and thus, $M_{j}$ ) is varied. The band of data on the right represents screech while there are two stages of transonic tones on the left, as indicated. The vertical lines in this figure demarcate flow regimes determined by one-dimensional nozzle flow analysis, based on the throat-to-exit area ratio. From the left, the first line (I) represents the condition when the throat is just choked, the second line (II) when the 'normal shock' is just at the exit and the third line (III) when the flow is perfectly expanded. Thus, to the left of line (I) the flow is subsonic, between I and II a shock is expected in the divergent section, between II and III the flow is overexpanded, and to the right of III the flow is underexpanded. While boundaries I and III are well represented, it is well known that boundary II is grossly underpredicted by 1-D analysis. In reality, for the nozzle under consideration boundary II is actually located far to the right at location II'. Thus, the transonic tone is seen to occur in the regime bounded by I and II' when a shock resides within the divergent section of the nozzle. Its mechanism is briefly as follows. The section of the nozzle downstream of the shock acts as a resonator having one end closed and the other open. Fundamental quarter-wave resonance corresponds to stage 1 marked in Figure 4. Resonance can also occur at odd harmonics, stage 2 in Figure 4 being the ${ }^{\text {rd }}$ harmonic (reader may look up (ref. 5) for further details).

From the evidence gathered so far (ref. 1), it appears that the broadband noise EBBN also takes place in the same flow regime ( $I-I^{\prime}$ ') when a shock resides within the divergent section. It should be noted that in order to study the broadband noise it is desirable that tones are not present. The transonic tones have been shown to be characteristic of nozzles with polished interiors. Suitable boundary layer tripping often suppresses the tones. As indicated in Section 2, most of the data in the following are presented for nozzles with tripped boundary layer. Here, it is also relevant to note that the flow coming out of the nozzle in the regime bounded by I and II', in the sense of one-dimensional analysis, may be expected to be subsonic and true overexpanded flow may be expected only in the range II'-III. In reality, however, when a shock resides within the nozzle the flow downstream separates and the ensuing jet contains shocks with characteristics similar to that of an overexpanded jet (refs. 1 and 5); hence the justification of the term 'overexpanded' used in the title of the paper. 
Representative sound pressure level spectra are documented in Figs. 5 through 11. These are shown as 'waterfall plots' for three values of $M_{j}\left(=0.6,1.2\right.$ and 1.8). The nozzle configuration and $M_{j}$ are indicated in the legend of each figure, (the first number is a record number retained for tracking purposes and should be ignored by the reader). For clarity only twelve spectral traces from alternate microphones are shown in each figure. The measurement angular location $(\theta)$ is indicated for two traces at the top and bottom, the others are at an interval of $10^{\circ}$. Note again that a smaller $\theta$ represents location closer to the downstream end of the jet. In Figure 5, for the M10T case, the traces are uneventful at the lowest $M_{j}$. Screech is noticed at $M_{j}=1.2$ while screech as well as clear BBSN are visible at the highest $M_{j}$. As is wellknown, the frequency of the BBSN peak increases with decreasing angular location, $\theta$. Small amplitude BBSN can also be discerned at $M_{j}=1.2$.

Similar trends are seen in Figures 6 and 7 for the M14T and M16T nozzles, respectively. In Figure 6, the peaks of BBSN are connected by a smooth curve, as an example; the intersection of such a curve with the individual traces allowed a clearer determination of the frequencies, to be documented in the appendix. In Figure 8, for the M18T case, BBSN or screech are practically absent at $M_{j}=1.8$, as expected, since the flow is fully expanded. At $M_{j}=0.6$ in Figure 8, it can be seen that the levels are generally elevated especially on the high frequency end; compare, for example, the (green) curves for $\theta=125^{\circ}$ between Figures 8 and 7. At $M_{j}=0.6$ the levels rise further with the M22T case in Figure 9. The elevation of the broadband levels at $M_{j}=0.6$ as well as at 1.2 , perhaps not completely clear from these plots, is illustrated further shortly. In Figure 10, for the largest design Mach number case (M28T), the amplitudes are actually smaller in general and this will also become clear with the following figures.

The transonic tone is clearly seen at the lowest $M_{j}$ for the untripped M22 nozzle (Fig. 11). The effect of the tripping can be appreciated by comparing with corresponding data in Figure 9 . The fundamental tone frequency in Figure 11 is $1170 \mathrm{~Hz}$. From correlations provided in (ref. 5) it can be inferred that this is a tone in stage 2. With a half-angle of $5^{\circ}$ for the given nozzle and $M_{j}=0.6$ the tone frequency for stage 2 can be calculated as $1120 \mathrm{~Hz}$, agreeing reasonably with the observation. Note that for $M_{j}=0.6$ in Figure 9, even with the trip a small peak is observed around $1170 \mathrm{~Hz}$. Similarly, a small peak near the expected transonic tone is also observed for the M28T case in Figure 10 at $M_{j}=0.6$. Thus, even with boundary layer trip residues of the transonic tone often persist although the spectra are by and large broadband in nature. It may also be noted that the trips do not affect screech or BBSN. This can be readily seen by comparing the spectra for $M_{j}=1.8$ between Figures 9 and 11 .

By inspecting the values given in table 1, it can be inferred that for all C-D nozzles the shock is inside the divergent section at $M_{j}=0.6$. Even though the boundary II' (Fig. 4) was not measured for the present nozzles, all C-D cases are also likely to involve an internal shock at $M_{j}=1.2$, perhaps, with the exception of the M14 case. At $M_{j}=1.8$, on the other hand, the shock is thought to be outside for all cases.

The overall sound pressure levels (OASPL) are calculated by integration of the spectra. OASPL for $\theta=90^{\circ}$ are shown in Figure 12 for the seven nozzles, as a function of $M_{j}$. For the convergent (M10T) case, the amplitudes are large for $M_{j}>1.2$ partly due to screech. For $M_{j}$ less than about 1 , the levels are seen to be larger with the C-D cases. It is also clear that the increase in the level is more with increasing design Mach number of the nozzle. For the M22 case, there is an additional bulge due to the transonic tones. Ignoring the latter case, it is clear from the spectral traces that the excess noise occurs primarily due to an increase in the broadband levels.

Before proceeding with further results from the present experiment, a comparison is shown in Figure 13 with data taken earlier with the same nozzles in another facility (' $\mathrm{CW} 17$ ') that were given in the extended abstract of this paper. As stated before, the latter facility was semi-anechoic and the data were taken with microphones only at $\theta=90^{\circ}$ and $25^{\circ}$. OASPL versus $M_{j}$ at $\theta=90^{\circ}$ are compared for only three nozzles for clarity. It is noted that the amplitudes are somewhat different in the range $M_{j}>1.2$ presumably because screech characteristics differed depending on the details of the nozzle attachments and facility geometry. At very low $M_{j}$, higher levels are indicated in CW17 apparently due to valve noise becoming prominent. Nevertheless, the agreement is excellent over the range $0.5<M_{j}<1.2$, exhibiting the occurrence 
of the excess noise in either facility. This should put to rest any doubt that the EBBN could be spurious and facility dependent.

OASPL data corresponding to Figure 12 are shown in Figure 14 for a shallow angle, $\theta=25^{\circ}$. The occurrence of EBBN can be observed, however, the threshold of $M_{j}$ below which it occurs is found to be lower. Also, the increases in the levels are smaller. These data trends become clearer with the directivity plots shown in the following. In Figure 14, it is also noted that the levels for the M28T case are significantly lower at high $M_{j}$. The levels for M22 and M22T cases are also low. This is apparently due to lower flow rates with the higher $M_{D}$ nozzles since the throat diameters are smaller. Note that with the M28 nozzle the throat diameter is about $1 / 2$ and, thus, the mass flow rate is about $1 / 4^{\text {th }}$ relative to the convergent case, for a given $N P R$ (or $M_{j}$ ). Massive boundary layer separation within the divergent section is also expected with the higher $M_{D}$ nozzles.

Directivity plots (OASPL versus $\theta$ ) are shown in Figures 15 through 18 , for four values of $M_{j}(0.6$, $1.0,1.4$ and 1.8). In each figure, the OASPL data (as measured) are shown for the six nozzles. At $M_{j}=0.6$ in Figure 15, the occurrence of EBBN is abundantly clear with the three nozzles having the largest design Mach number. Insignificant differences are noted among data from the M10T, M14T and M16T cases. The amplitudes increase clearly with M18T, there is a large further increase with M22T but the amplitudes fall back somewhat with the M28T nozzle. As discussed in the previous paragraph, the mass flow rate with the M28T nozzle is about $1 / 4^{\text {th }}$ of that with the convergent one. Notice that a huge increase in EBBN takes place in spite of the smaller flow rate. However, in the limit $M_{D} \rightarrow \infty$, the mass flow rate and hence the noise would tend to be zero and a reversal in the data trend with increasing $M_{D}$ is naturally expected. This reversal has apparently ensued when going from the M22 to the M28 case. In Figure 15, it can also be seen that at shallow angles the relative increase in OASPL is small. This provides a clearer perspective with regards to the lower amplitudes noted in Figure 14. At $M_{j}=1.0$, in Figure 16, EBBN is also quite prominent and similar trends are noted as seen in Figure 15. Here, the M14T and M16T nozzles are also seen to involve higher amplitudes at larger values of $\theta$. However, overall, the increases in the levels relative to the convergent case are not as large as seen at $M_{j}=0.6$.

At $M_{j}=1.4$ and 1.8 (Figs. 17 and 18), the trends become murky partly because of the occurrence of screech and BBSN. The M10T and M14T cases have the largest amplitudes and there is no evidence of excess OASPL with the C-D nozzles. With M14T case in Figure 17, the flow is fully expanded since $M_{j}=1.4$. Thus, for this case the levels are found to be generally low, as expected. This is especially true at the high end of the $\theta$-range where the noise from the imperfectly expanded jets is dominated by screech and BBSN. The amplitudes are seen to be smaller at shallow angles with the two nozzles having the largest $M_{D}$ due to reasons explained already. Essentially the same comments can be made from Figure 18 where the M18T nozzle has fully expanded flow and hence the least noise.

The data presented so far are as measured. Should the trends for EBBN be different had the throat diameters been used for data normalization? That is, what would happen if the throat diameter, instead of the exit diameter, was kept a constant in the experiment? This is examined in Figure 19 where the data of Figure 16 are replotted with the intensity normalized as, $I^{*}=I\left(D_{e} / D_{t}\right)^{2}$. As expected, the excess amplitudes have become amplified and more prominent. The same conclusion is reached when the data of Figure 12 are scaled by the throat diameters, as shown in Figure 20. The increases in the noise levels with the present nozzles shown with OASPL values as measured are thus conservative. That the C-D nozzles are noisier in the low $M_{j}$ range due to EBBN is established beyond any doubt.

Finally, the overall power levels (PWL) are calculated by integration of the data from the 24 microphones. The PWL data are shown in Figure 21. The trends are essentially the same as seen with the OASPL data for $\theta=90^{\circ}$ (Fig. 12). Thus, the total power of the radiated sound is high in the $M_{j}$ range where EBBN occurs, and the phenomenon is not just characteristic of specific angular locations. Furthermore, since EBBN involves broadband components, a similar increase in the levels would be expected if other metrics for jet noise, such as EPNdB, were used. 


\section{Concluding Remarks}

Results of an experiment on the characteristics of an excess noise occurring with convergentdivergent nozzles in the overexpanded regime are presented in this paper. Data are obtained with five C-D nozzles and compared with that from a convergent nozzle. The results clearly establish that the C-D nozzles are noisier in the low Mach number range of the overexpanded regime. This is shown by comparison of directivity patterns as well as overall radiated power calculations. The excess amplitude is most pronounced around $\theta=45^{\circ}$ and is prominent at larger angles. At shallow angles near the jet's downstream edge, it may not be clearly noticed.

The excess noise occurs even if there are no tones present and the spectral distribution is broadband, hence the term excess broadband noise (EBBN). With earlier results shown in (ref. 1), it is clear that the EBBN takes place roughly in the same $M_{j}$-range where transonic tones are expected with a nozzle having a smooth interior. This leads to the belief that EBBN and the transonic tones are similar in morphology. Both trace to unsteady shock motion within the divergent section. With a smooth interior, providing azimuthal symmetry, the unsteady shock motion locks on to a resonance generating the transonic tones. With a larger practical nozzle, or boundary layer trip with the model-scale nozzles, a breakdown in azimuthal symmetry apparently prevents the resonance leading to a random unsteady motion. The latter gives rise to the observed increase in the noise levels that are broadband in nature.

As discussed in (ref. 1), the EBBN is distinct in characteristics from BBSN. A clear trend of BBSN, as also documented in the appendix from the present data, is a decreasing frequency of the peak with increasing angle. This is not the case with EBBN and the spectral shape appears more or less similar in all directions. It is possible that EBBN and BBSN are mutually exclusive. With a given C-D nozzle when one occurs the other may not. BBSN occurs when the shock from the divergent section is pushed out and a periodic train of strong shocks is formed outside the nozzle. On the other hand, EBBN occurs at lower pressure ratios when the shock is inside.

How relevant is EBBN in practical applications? Since it occurs at lower pressure ratios at the onset of the overexpanded regime, it may not be of concern in typical flight conditions. This might be the reason why the phenomenon, to the best of our knowledge, has gone practically unrecognized in the vast literature on jet noise. However, there could be situations, e.g., the climb-to-cruise stage of certain fighter jets when the engine involves overexpanded exhaust (refs. 6 to 8), rocket nozzles in launch pad environment (see, for example, (ref. 9)), where it might be relevant. It is needless to say, however, that one must be aware of its existence especially in efforts to simulate and predict supersonic jet noise accurately.

\section{Appendix}

Figures A1 and A2 are included as side observations made during the course of this investigation. Figure A1 shows measured mass flow rate in comparison to one-dimensional nozzle flow calculations. The agreements are found to be excellent. It was thought that with massive separation for the large $M_{D}$ cases there might be some difference. Apparently, the throat and the pressure ratio determine the mass flow rates that are not impacted by flow separation within the divergent section. Only at very low $M_{j}$, significant difference is noted especially for the M28T case. Presumably the separation location encroaches far enough upstream to affect the throat characteristics.

As mentioned during the discussion of Figure 6, the BBSN peak frequencies $\left(f_{p}\right)$ were approximately read off from the data wherever they were clear. The variations of $f_{p}$ with $\theta$ are shown in Figure A2. For clarity the data are shown in two sets as identified in the legends. A decreasing $f_{p}$ with increasing $\theta$ is a characteristic of BBSN observed and explained in References 10 and 2. No attempt is made in this paper to compare these data with available predictions. 


\section{References}

1. K.B.M.Q. Zaman, "Noise characteristics of overexpanded jets from convergent-divergent nozzles," AIAA Paper 2008-25, $46^{\text {th }}$ Aerospace Sciences Meeting, Reno, NV, 7-11 Jan., 2008.

2. C.K.W. Tam and H.K. Tanna, "Shock associated noise of supersonic jets from convergent-divergent nozzles," J. Sound \& Vib., 81(3), pp. 337-358, 1982.

3. C.K.W. Tam, "Supersonic jet noise," Ann. Review Fluid Mech., 27, pp. 17-43, 1995.

4. J.E. Bridges, C. A. Brown, "Validation of the Small Hot Jet Acoustic Rig for Jet Noise Research," AIAA-2005-2846, 2005.

5. K.B.M.Q. Zaman, M.D. Dahl, T.J. Bencic and C.Y. Loh, "Investigation of a 'transonic resonance' with convergent-divergent nozzles," J. Fluid Mech., 463, pp. 313-343, 2002.

6. B. Greska, A. Krothapalli, and V. Arakeri, "A further investigation into the effects of microjets on high speed jet noise," AIAA Paper 2003-3128, $9^{\text {th }}$ AIAA/CEAS Aeroacoustics Conference, Hilton Head, SC, 12-14 May, 2003.

7. T.D. Norum, D.P. Garber, R.A. Golub, O.L. Santa Maria and J.S. Orme, "Supersonic jet exhaust noise at high subsonic flight speed,"NASA/TP_-2004-212686, January, 2004.

8. J.M. Seiner, B.J. Jansen and L.S. Ukeiley, "Acoustic fly-over studies of F/A E/F Aircraft during FCLP mission," AIAA Paper 2003-3330, $9^{\text {th }}$ AIAA/CEAS Aeroacoustics Conference, Hilton Head, SC, 12-14 May, 2003.

9. Kandula, M., "Prediction of turbulent jet mixing noise reduction by water injection," $A I A A J ., 46(11)$, pp. 2714-2722, 2008.

10. M. Harper-Bourne and M.J. Fisher, "The noise from shock waves in supersonic jets," Proc. AGARD Conf. on noise mechanisms (No. 131), Brussels, Belgium, 1973. 


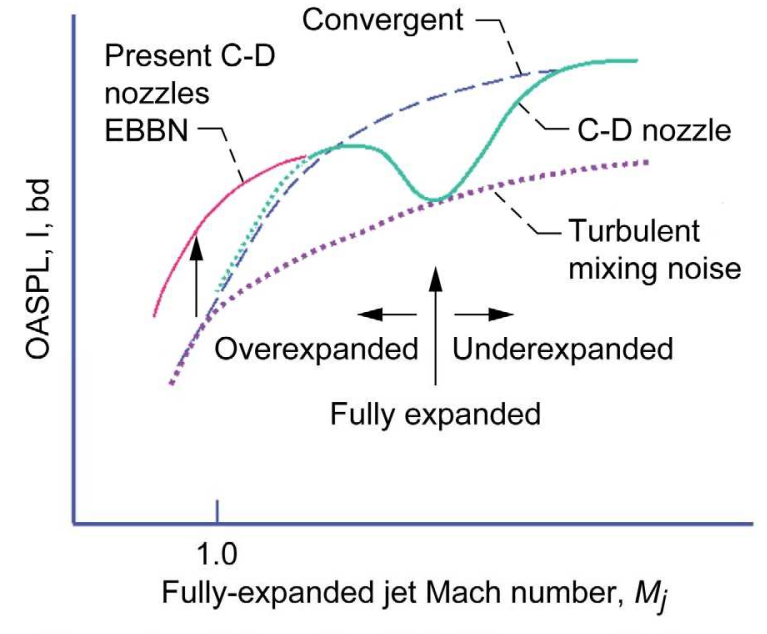

Figure 1.- Schematic of OASPL versus $M_{j}$ for C-D and convergent nozzles, after Reference 2.

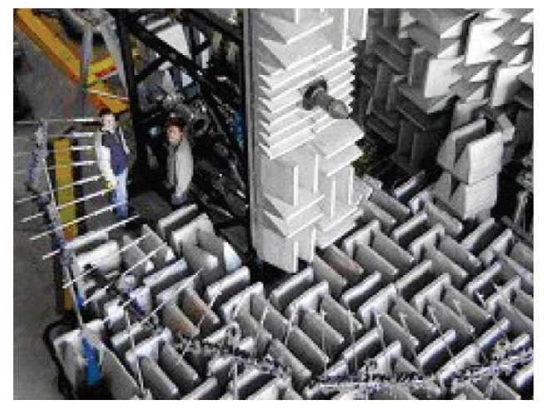

Figure 2.-The SHJAR viewed from above. The 24-microphone array is located on a $100 \mathrm{in}$. radius covering angles $15^{\circ}<\theta<130^{\circ} ; \theta$ is referenced to downstream jet axis. The nozzle and microphones are 8' above the wedge tips.

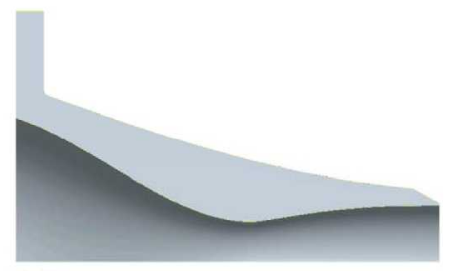

(a)
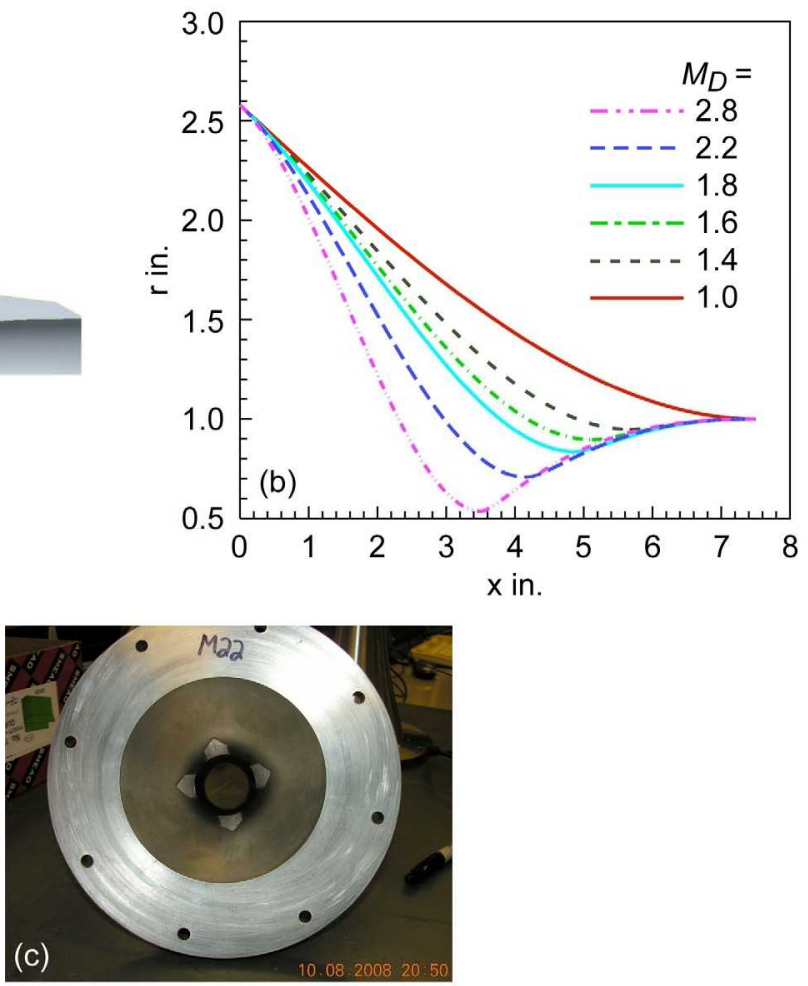

Figure 3.-Nozzles: (a) Computer-aided-design drawing of one of the C-D nozzles. (b) Internal contours of all nozzles. (c) Picture of M22T. 


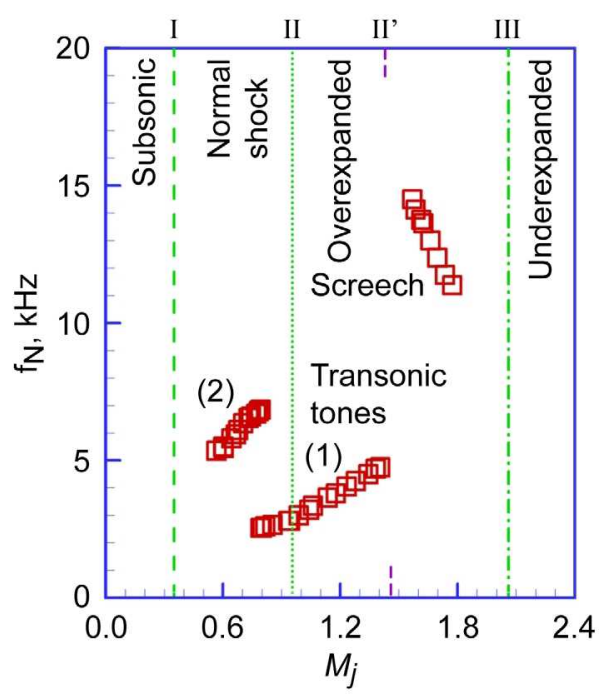

Figure 4.-Variation of frequencies of transonic tone and screech with $M_{j}$ for a small C-D nozzle $\left(D_{t}=0.3\right.$ in., $D_{e}=0.4$ in.), from 5 .
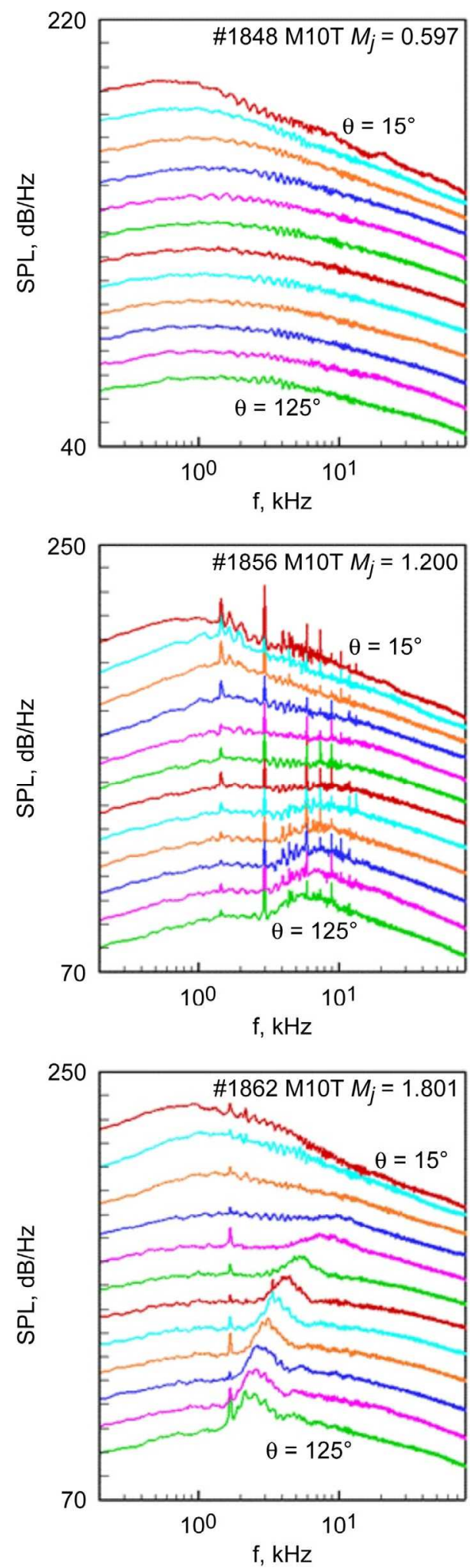

Figure 5.-SPL spectra for nozzle M10T. In each set, data are for different $\theta$, at increment of $10^{\circ}$. Ordinate pertains to curve for $\theta=125^{\circ}$, successive curves shifted by $10 \mathrm{~dB}$. 

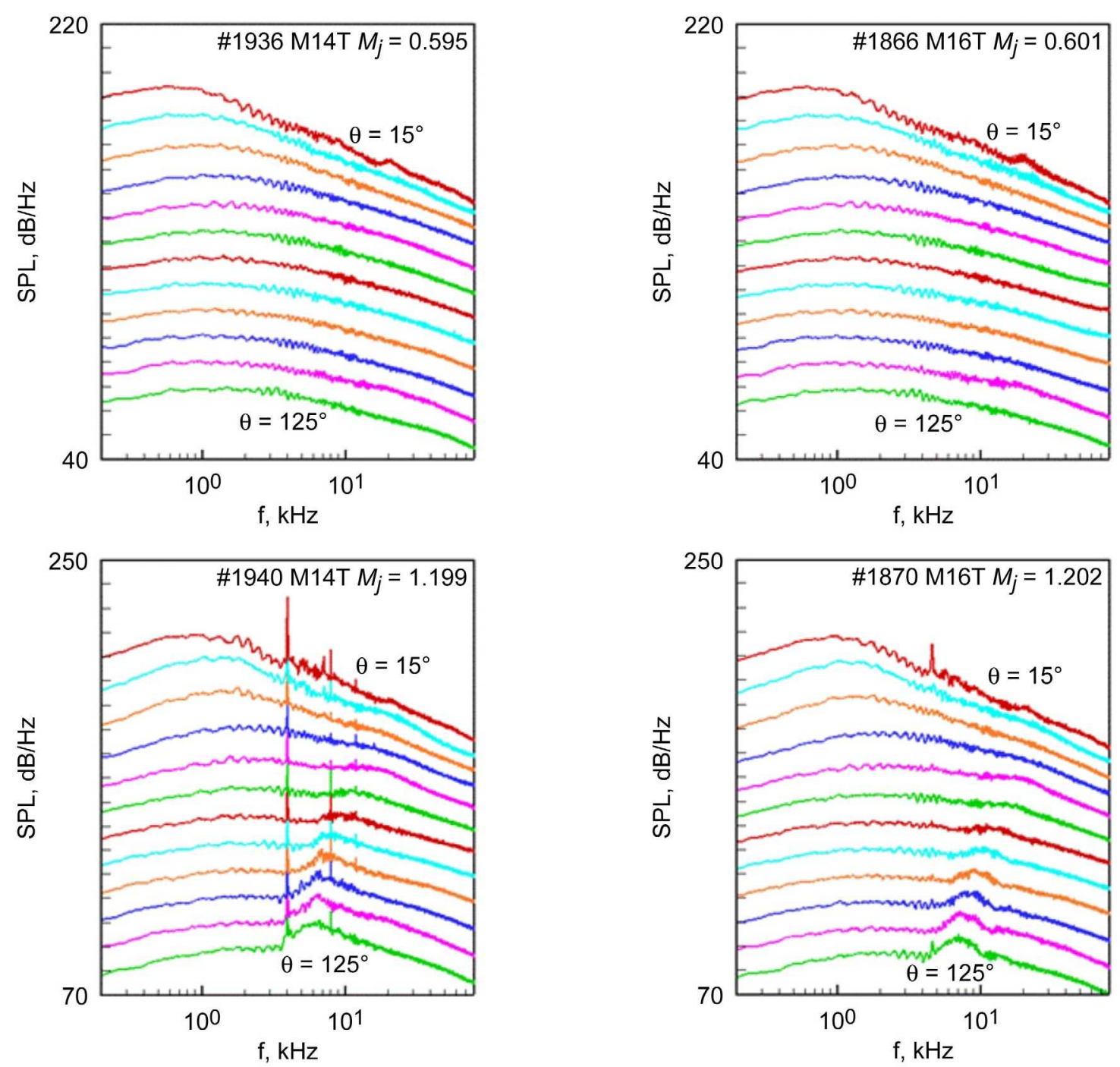

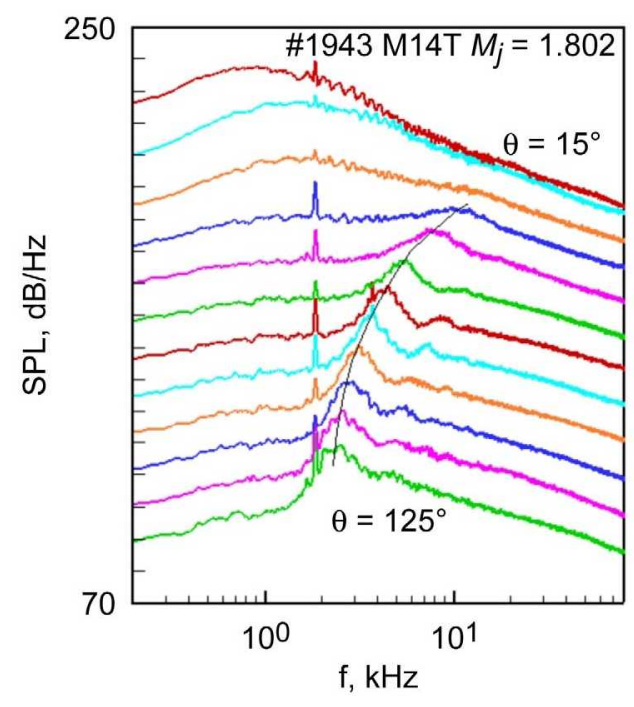

Figure 6.-SPL spectra for nozzle M14T, shown similarly as in Fig. 5 .

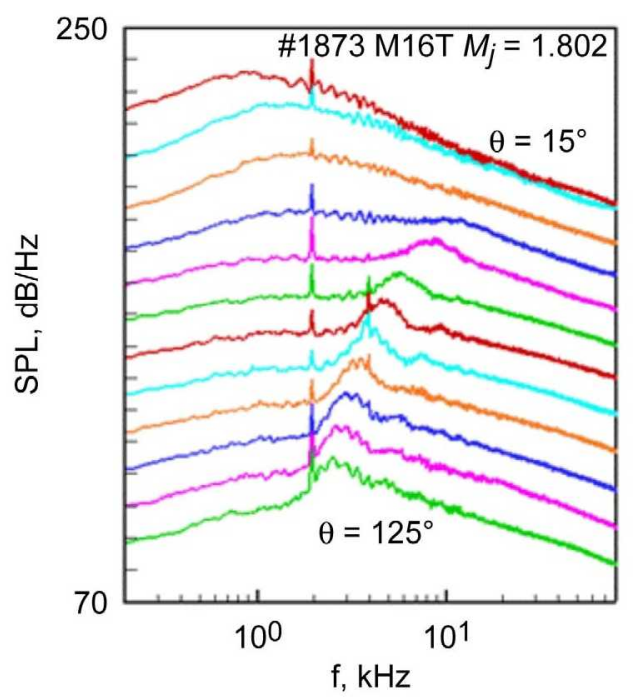

Figure 7.-SPL spectra for nozzle M16T, shown similarly as in Fig. 5. 

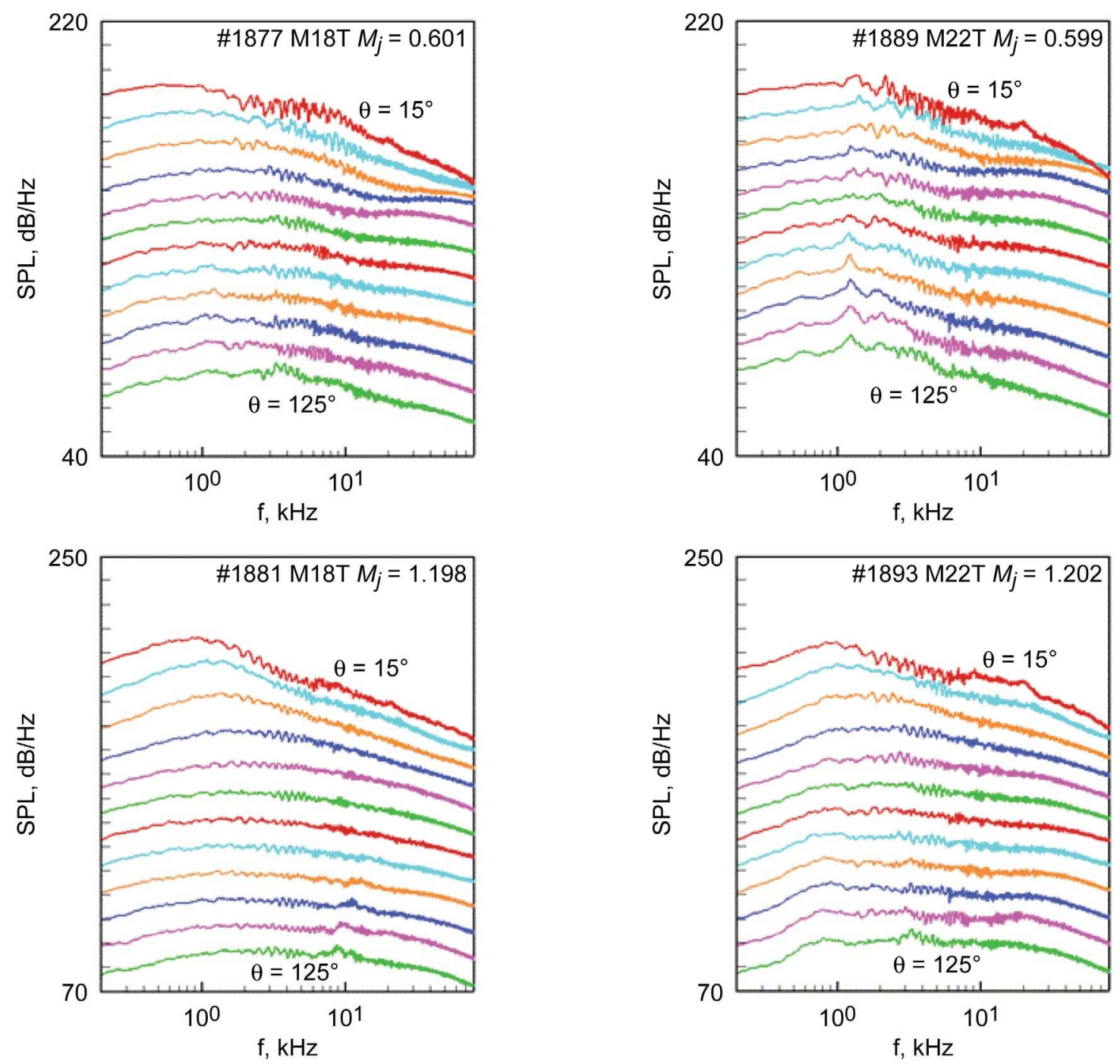

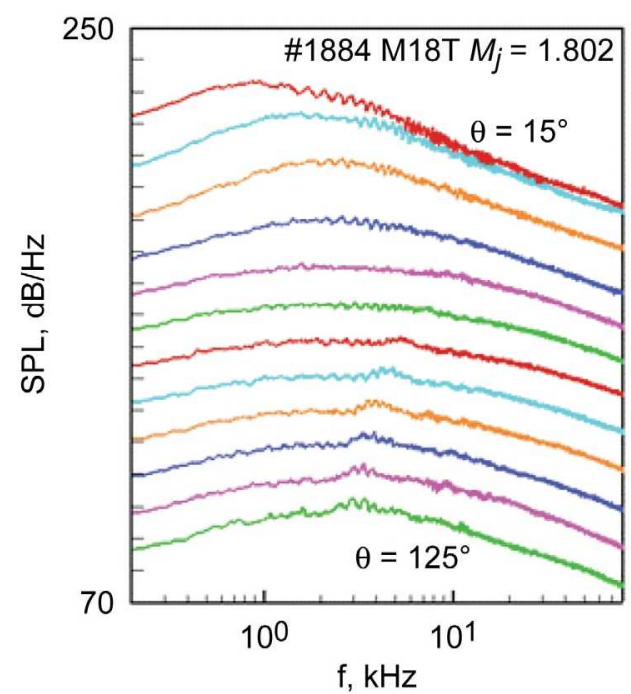

Figure 8.-SPL spectra for nozzle M18T, shown similarly as in Fig. 5.

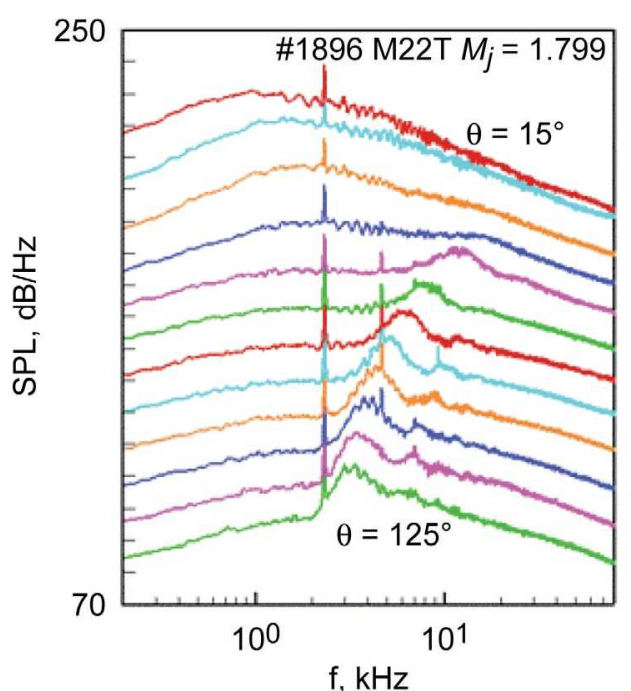

Figure 9.-SPL spectra for nozzle M22T, shown similarly as in Fig. 5. 

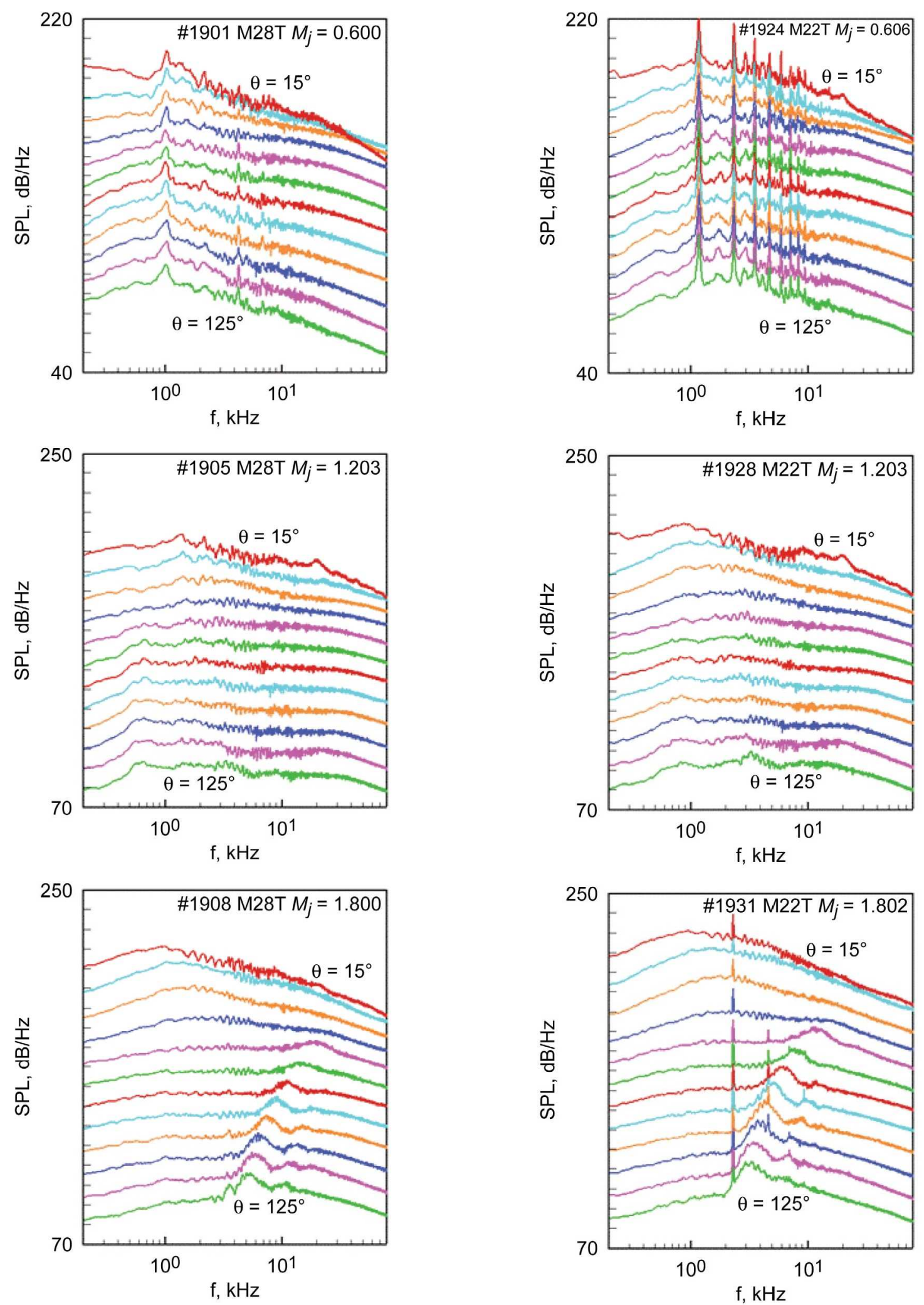

Figure 10.-SPL spectra for nozzle M28T, shown similarly as in Fig. 5.

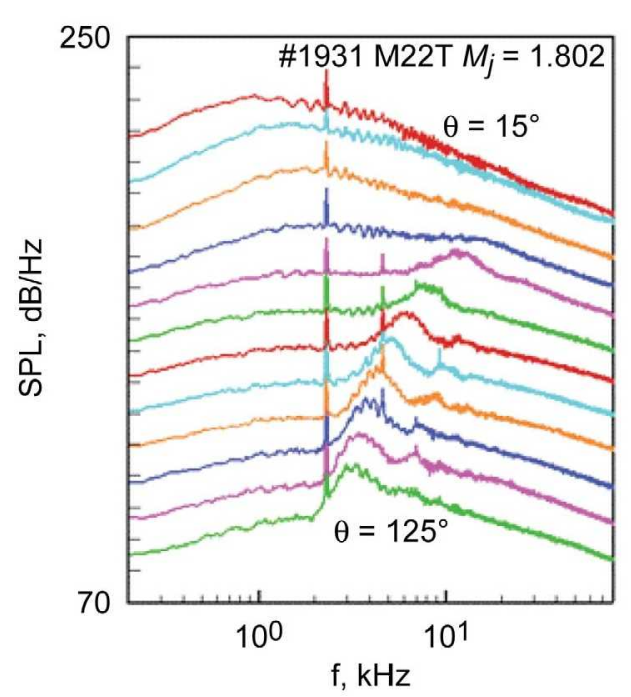

Figure 11.-SPL spectra for nozzle M22T, shown similarly as in Fig. 5. 


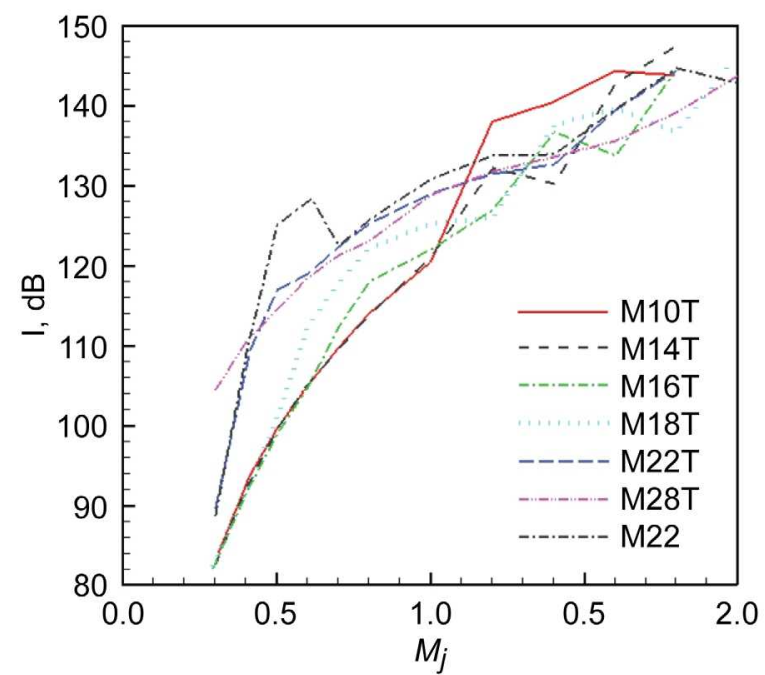

Figure 12. $-\mathrm{OASPL}$ at $\theta=90^{\circ}$, as a function of $M_{j}$ for all nozzles.

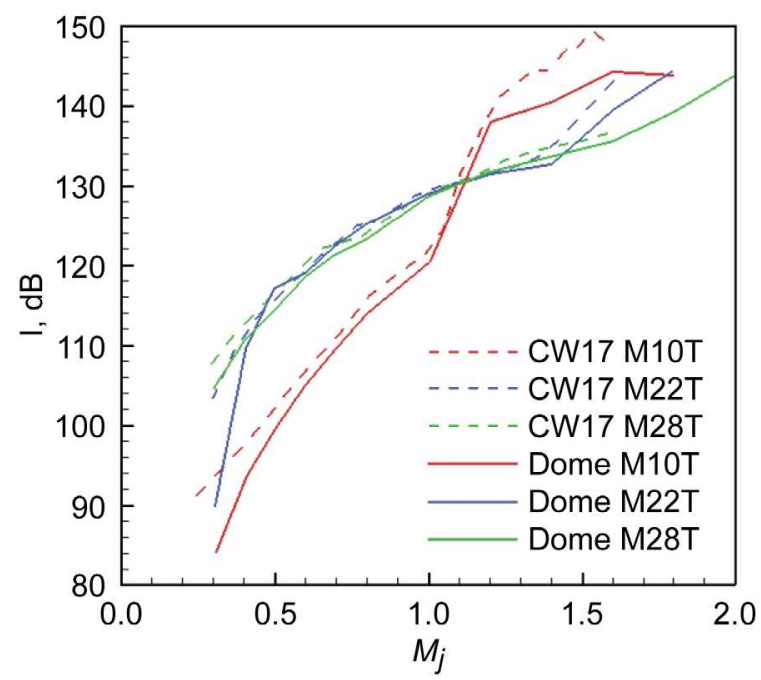

Figure 13.-OASPL at $\theta=90^{\circ}$, as a function of $M_{j}$ for three nozzles, as indicated. Comparison of present data (Dome) with data taken earlier in another facility (CW17).

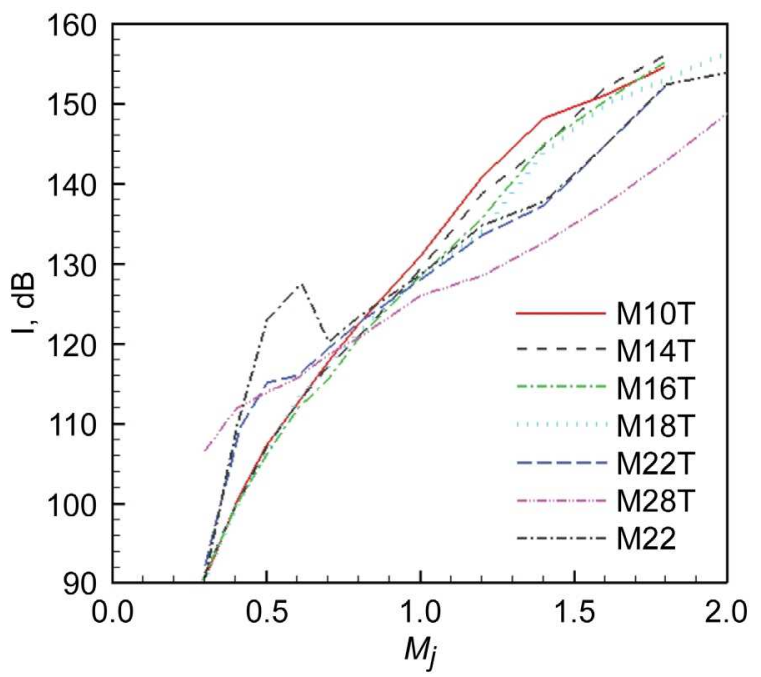

Figure 14.-OASPL at $\theta=25^{\circ}$, as a function of $M_{j}$ for all nozzles.

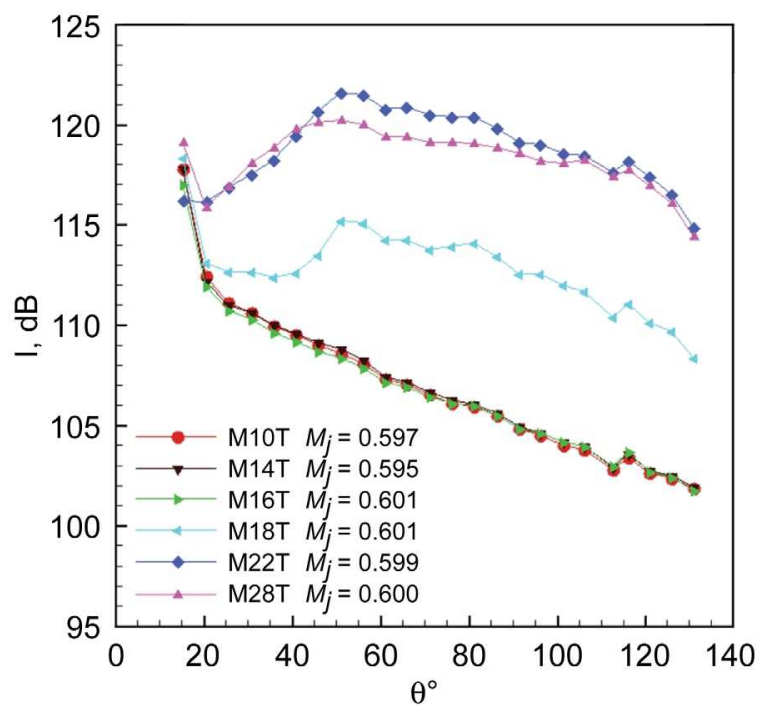

Figure 15.-OASPL versus $\theta$ for different nozzles, as indicated; $M_{j} \approx 0.6$. 


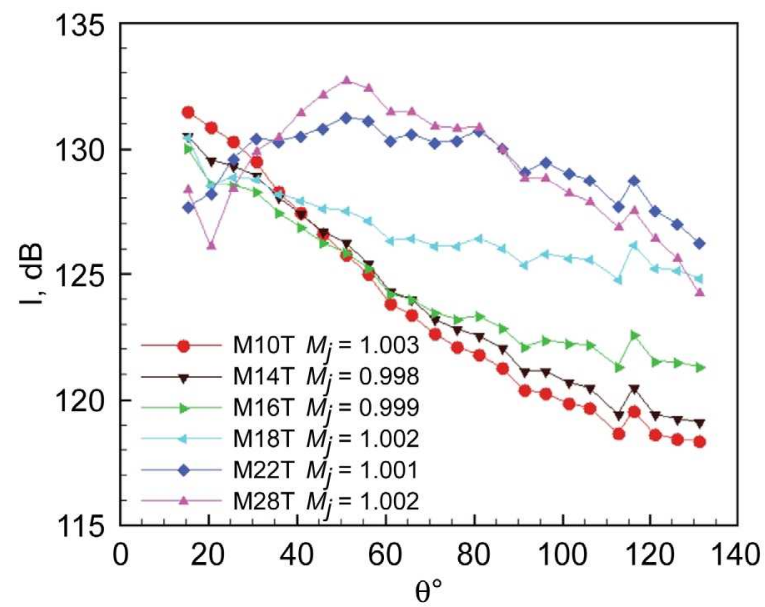

Figure 16.-OASPL versus $\theta$ for different nozzles, as indicated; $M_{j} \approx 1.0$.

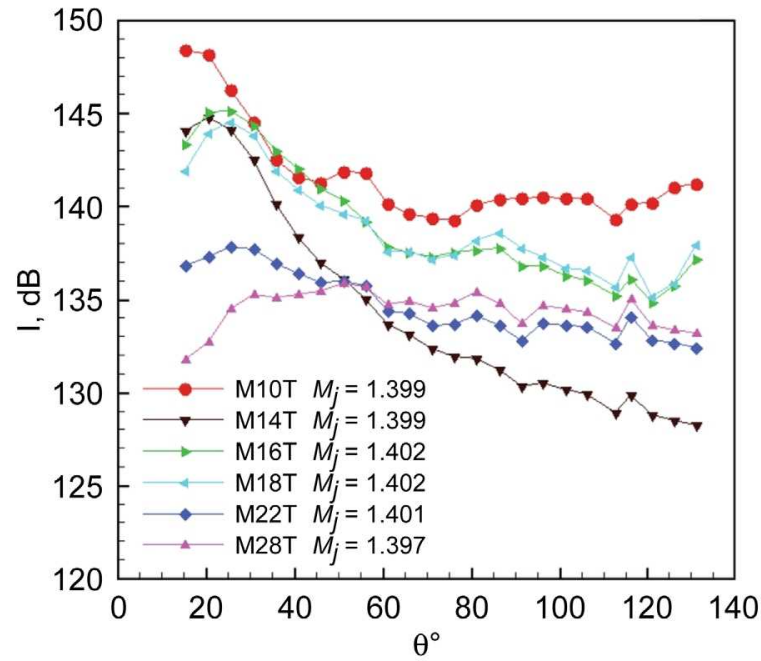

Figure 17.-OASPL versus $\theta$ for different nozzles, as indicated; $M_{j} \approx 1.4$.

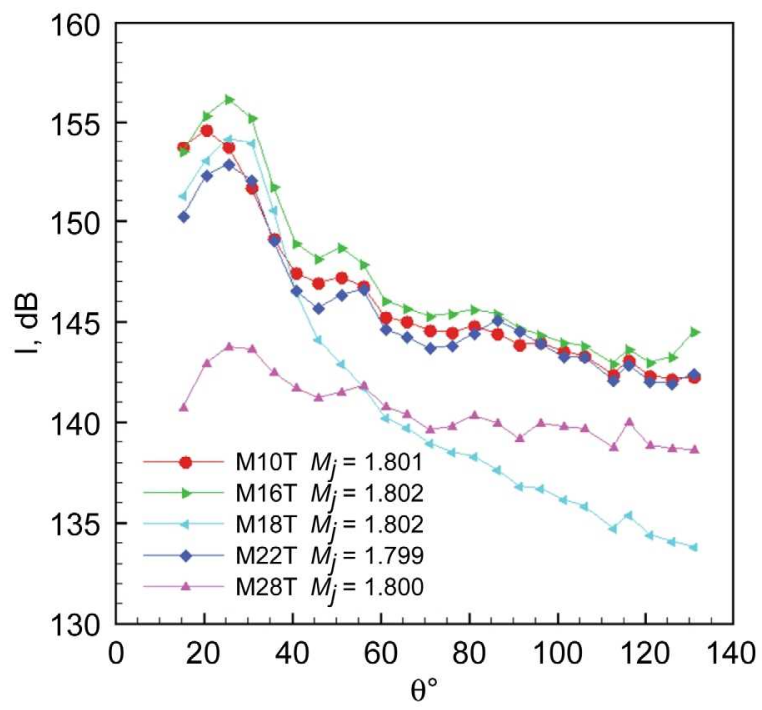

Figure 18.-OASPL versus $\theta$ for different nozzles, as indicated; $M_{j} \approx 1.8$.

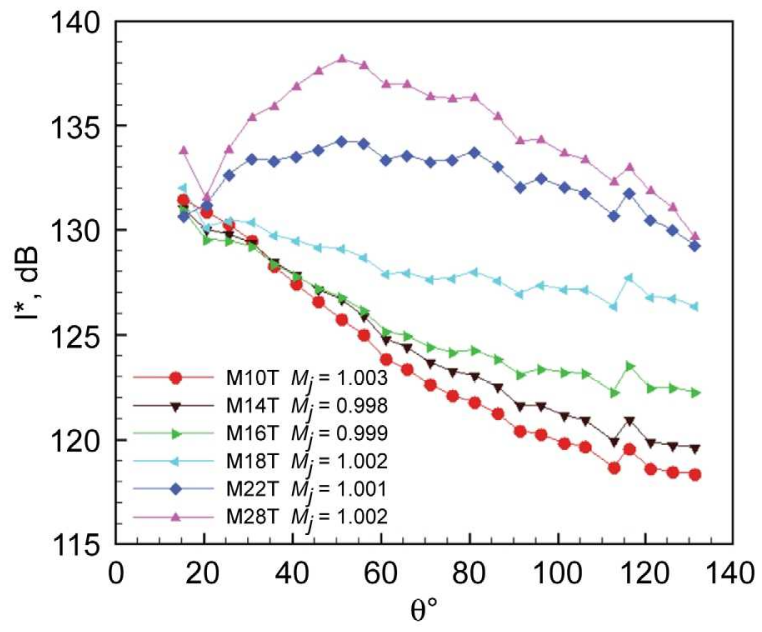

Figure 19.-OASPL, normalized by throat diameter, versus $\theta$ for different nozzles; $M_{j} \approx 1.0$ (data corresponding to Fig. 16). 


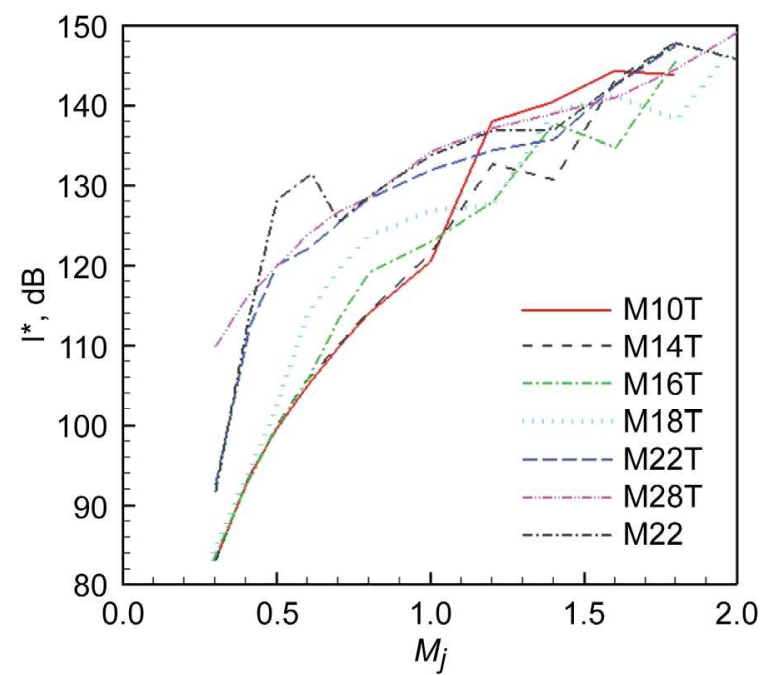

Figure 20.-OASPL, normalized by throat diameter, versus $M_{j}$ for different nozzles; $\theta=90^{\circ}$ (data corresponding to Fig. 12).

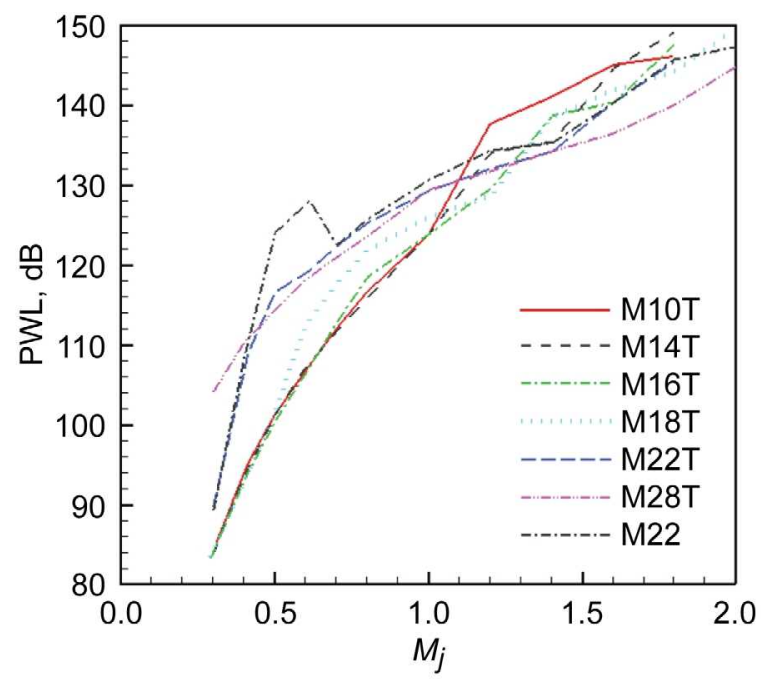

Figure 21.-Relative power level of radiated noise versus $M_{j}$ for different nozzles.

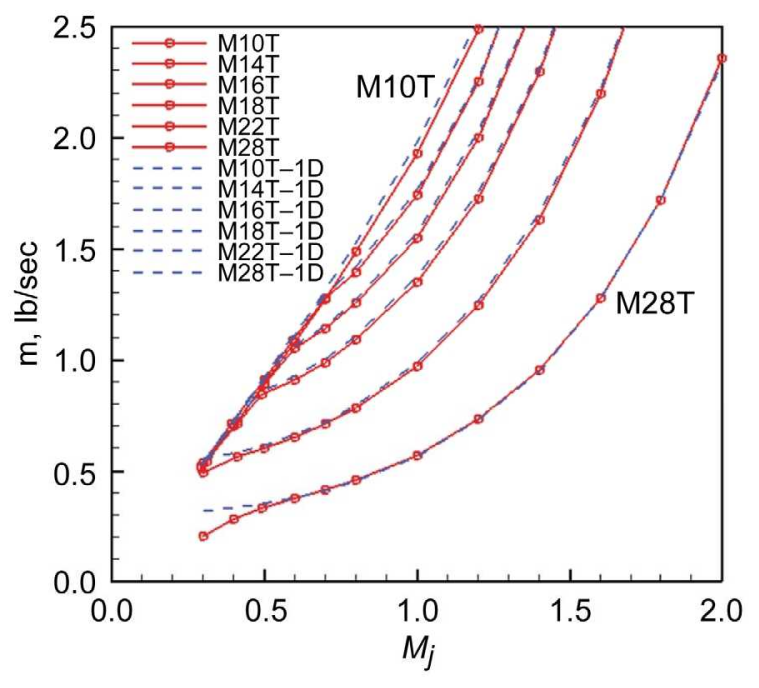

Figure A1.-Mass flux versus $M_{j}$, measured data (red lines) compared to one-dimensional nozzle flow prediction (blue dashed lines). 

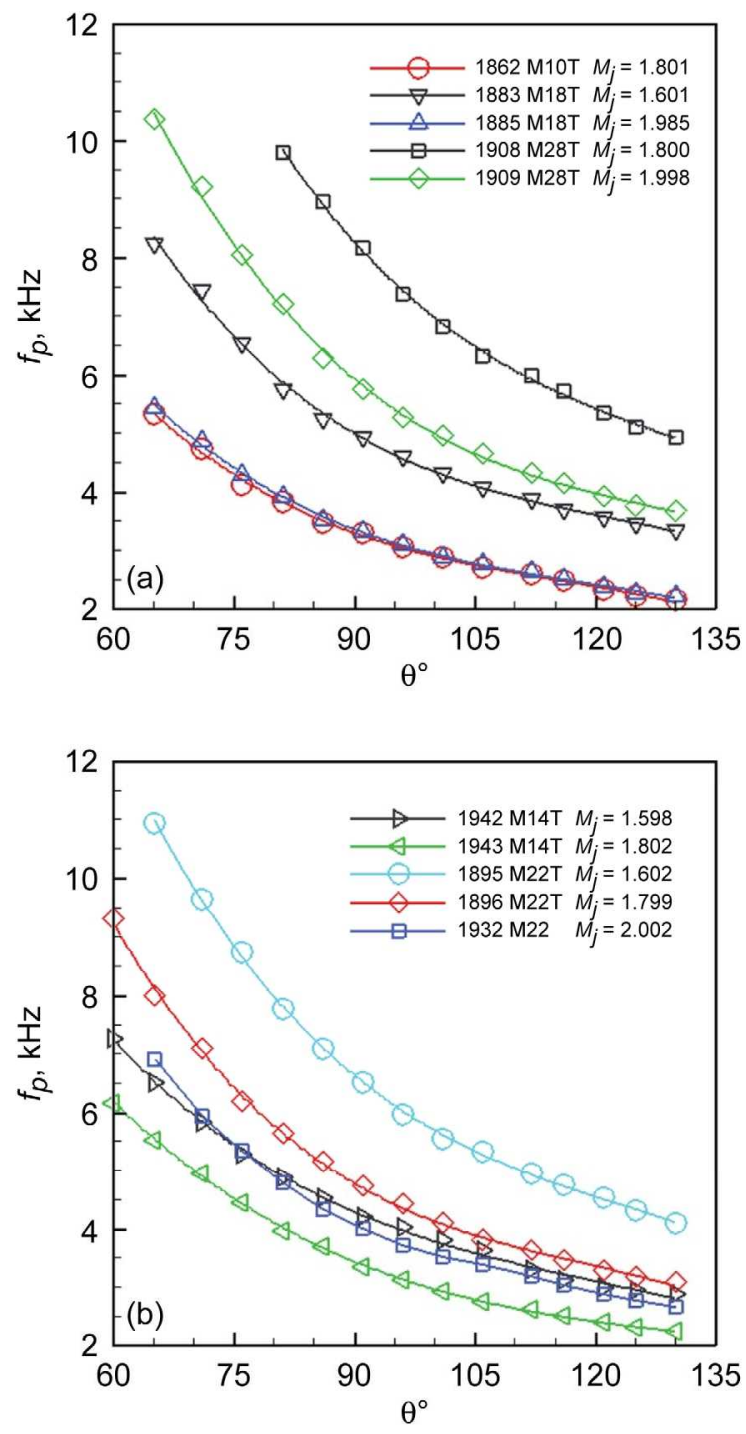

Figure A2.-BBSN peak frequency versus. Data shown in two sets for clarity: (a) M10T, M18T and M28T cases. (b) M14T and M22T cases. 


\begin{tabular}{|c|c|c|}
\hline \multicolumn{2}{|c|}{ REPORT DOCUMENTATION PAGE } & $\begin{array}{c}\text { Form Approved } \\
\text { OMB No. 0704-0188 }\end{array}$ \\
\hline \multicolumn{3}{|c|}{ 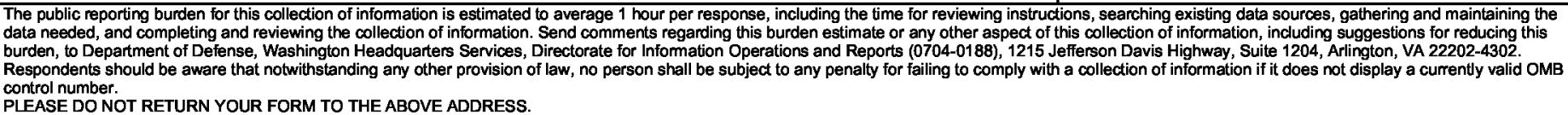 } \\
\hline $\begin{array}{l}\text { 1. REPORT DATE (DD-MM-YYYY) } \\
01-06-2009\end{array}$ & $\begin{array}{l}\text { 2. REPORT TYPE } \\
\text { Technical Memorandum }\end{array}$ & 3. DATES COVERED (From - To) \\
\hline \multirow{3}{*}{\multicolumn{2}{|c|}{$\begin{array}{l}\text { 4. TITLE AND SUBTITLE } \\
\text { An Excess Broadband Noise Observed With Overexpanded Jets }\end{array}$}} & 5a. CONTRACT NUMBER \\
\hline & & 5b. GRANT NUMBER \\
\hline & & 5c. PROGRAM ELEMENT NUMBER \\
\hline \multirow{3}{*}{\multicolumn{2}{|c|}{$\begin{array}{l}\text { 6. AUTHOR(S) } \\
\text { Zaman, K.B.M.Q.; Bridges, James, E.; Brown, C., A. }\end{array}$}} & 5d. PROJECT NUMBER \\
\hline & & 5e. TASK NUMBER \\
\hline & & $\begin{array}{l}\text { 5f. WORK UNIT NUMBER } \\
\text { WBS 984754.02.07.03.17.04 }\end{array}$ \\
\hline \multicolumn{2}{|c|}{$\begin{array}{l}\text { 7. PERFORMING ORGANIZATION NAME(S) AND ADDRESS(ES) } \\
\text { National Aeronautics and Space Administration } \\
\text { John H. Glenn Research Center at Lewis Field } \\
\text { Cleveland, Ohio } 44135-3191\end{array}$} & $\begin{array}{l}\text { 8. PERFORMING ORGANIZATION } \\
\text { REPORT NUMBER } \\
\text { E-16893 }\end{array}$ \\
\hline \multirow{2}{*}{\multicolumn{2}{|c|}{$\begin{array}{l}\text { 9. SPONSORING/MONITORING AGENCY NAME(S) AND ADDRESS(ES) } \\
\text { National Aeronautics and Space Administration } \\
\text { Washington, DC 20546-0001 }\end{array}$}} & $\begin{array}{l}\text { 10. SPONSORING/MONITOR'S } \\
\text { ACRONYM(S) } \\
\text { NASA }\end{array}$ \\
\hline & & $\begin{array}{l}\text { 11. SPONSORING/MONITORING } \\
\text { REPORT NUMBER } \\
\text { NASA/TM-2009-215603; AIAA-2009- } \\
0289\end{array}$ \\
\hline \multicolumn{3}{|c|}{$\begin{array}{l}\text { 12. DISTRIBUTION/AVAILABILITY STATEMENT } \\
\text { Unclassified-Unlimited } \\
\text { Subject Categories: } 02 \text { and } 07 \\
\text { Available electronically at http://gltrs.grc.nasa.gov } \\
\text { This publication is available from the NASA Center for AeroSpace Information, 301-621-0390 }\end{array}$} \\
\hline
\end{tabular}

\section{SUPPLEMENTARY NOTES}

\section{ABSTRACT}

Results of an experiment on the characteristics of an excess noise occurring with convergent-divergent (C-D) nozzles in the overexpanded regime are presented in this paper. Data are obtained with five C-D nozzles and a convergent nozzle, all having the same exit diameter. The results clearly establish that the C-D nozzles are noisier in the low Mach number range of the overexpanded regime. This is evidenced from the directivity patterns as well as overall radiated sound power calculations. The excess noise is broadband in nature and is found to be more pronounced with nozzles having a larger half-angle of the divergent section. It appears to occur when a shock resides within the divergent section and results from random unsteady motion of the shock.

15. SUBJECT TERMS

Jets; Noise; Shocks; Turbulence

\begin{tabular}{|l|l|l|l|l|l|}
\hline \multicolumn{2}{|l|}{ 16. SECURITY CLASSIFICATION OF: } & $\begin{array}{l}\text { 17. LIMITATION OF } \\
\text { ABSTRACT }\end{array}$ & $\begin{array}{l}\text { 18. NUMBER } \\
\text { OF } \\
\text { PAGES }\end{array}$ & $\begin{array}{l}\text { 19a. NAME OF RESPONSIBLE PERSON } \\
\text { STI Help Desk (email:help@sti.nasa.gov) }\end{array}$ \\
\cline { 1 - 1 } $\begin{array}{l}\text { a. REPORT } \\
\text { U }\end{array}$ & $\begin{array}{l}\text { b. ABSTRACT } \\
\text { U }\end{array}$ & $\begin{array}{l}\text { c. THIS } \\
\text { PAGE } \\
\text { U }\end{array}$ & UU & 22 & $\begin{array}{l}\text { 19b. TELEPHONE NUMBER (include area code) } \\
301-621-0390\end{array}$ \\
\hline
\end{tabular}



